\title{
Associations of physical activity at work and household income with obesity: a cross-sectional study among rural adults in Korea
}

\author{
Su Yeon Kye ${ }^{1}$, Heeyoun Cho', Tran Thi Phuong Thao ${ }^{2}$, Jin-Kyoung Oh ${ }^{2,3}$, Min Kyung Lim² \\ 'Division of Cancer Control and Policy, National Cancer Control Institute, National Cancer Center, Goyang, Korea; ${ }^{2}$ Department of Cancer \\ Control and Population Health, Graduate School of Cancer Science and Policy, National Cancer Center, Goyang, Korea; ${ }^{3}$ Division of Cancer \\ Prevention and Early Detection, National Cancer Control Institute, National Cancer Center, Goyang, Korea
}

OBJECTIVES: This study was performed to identify the effect of physical activity at work on obesity and to analyze the contribution of socioeconomic factors and health behaviors to this association, which has been relatively little studied.

METHODS: From the Korean National Cancer Center Community Cohort, a total of 5,587 adults (2,125 men; 3,462 women) aged more than 30 years living in rural areas were enrolled. Information on socio-demographic factors, health behaviors, and body mass index was gathered using face-to-face interviews and measurements of height and weight.

RESULTS: Inverse associations were identified between vigorous-intensity physical activity at work and obesity in both men and women, while no association was found between vigorous-intensity physical activity during leisure time and obesity. High household income was independently associated with a lower risk of obesity among those who had low levels of vigorous-intensity physical activity at work. Vigorous physical activity at work showed an inverse association with obesity in rural areas where heavy manual labor is common.

CONCLUSIONS: Our findings indicate the necessity to account for various types of physical activity to improve the assessment and prevention of obesity.

KEY WORDS: Exercise, Obesity, Rural population, Adult, Korea

\section{INTRODUCTION}

Evidence has shown that physical activity (PA) is a major determinant of obesity. Therefore, accelerating engagement in PA plays a crucial significant role in fighting the obesity epidemic, espe-

\section{Correspondence: Min Kyung Lim}

Department of Cancer Control and Population Health, Graduate

School of Cancer Science and Policy, National Cancer Center,

323 Ilsan-ro, Ilsandong-gu, Goyang 10408, Korea

E-mail: mickey@ncc.re.kr

Received: Nov 5, 2020 / Accepted: Dec 25, 2020 / Published: Dec 29, 2020

This article is available from: https://e-epih.org/

(c) This is an open-access article distributed under the terms of the Creative Commons Attribution License (https://creativecommons.org/licenses/by/4.0/), which permits unrestricted use, distribution, and reproduction in any medium, provided the original work is properly cited.

(C) 2021, Korean Society of Epidemiology cially in modern societies wherein excess energy intake from food or drinks is predominant [1]. Although recommended efforts have been implemented as interventions, the prevalence of obesity has yet to significantly decrease in a single country worldwide [2]. Furthermore, it is predicted to dramatically increase along with the rising global burden of obesity-related diseases in upcoming years [3]. Therefore, more concerted efforts are needed to create PA interventions and to improve obesity prevention strategies globally.

Numerous studies have investigated the role of PA in obesity to suggest appropriate interventions for preventing weight gain and maintaining a healthy weight. However, most researchers have focused on leisure-time PA [4-7] and have not accounted for other domains, including occupational, transportation, and household PA $[8,9]$. Thus, it is necessary to identify how various patterns of PA affect obesity to obtain a more comprehensive understanding 
of the association between PA and obesity. In particular, although occupational PA also has a significant impact on total caloric expenditure, few studies have assessed occupational PA together with leisure-time PA in detail [10,11].

People living in developed countries such as Korea have double the risk of developing obesity as those in low-income and middleincome countries [2]. In Korea, the prevalence of obesity dramatically increased from $25 \%$ to $43 \%$ among men from 1998 to 2018 , but stabilized at $26 \%$ among women. By 2030 , the prevalence of obesity is estimated to reach $62 \%$ for men and $37 \%$ for women $[12,13]$. Meanwhile, the frequency of leisure-time PAs was recently found to be very low among the Korean population. In particular, $50 \%$ of Koreans reported no weekly moderate-intensity to vigorous-intensity PAs, and only $20 \%$ reported participating in such activities 1-2 times/wk [14]. Moreover, most studies have focused on the effects of leisure-time PAs on obesity, while only limited research has explored the various patterns of PA and obesity among more neglected classes of people, including older adults, those living in rural areas, and those with low economic status. Therefore, the present study aimed to investigate the associations of PA during leisure and at work with obesity among adults in rural Korea.

\section{MATERIALS AND METHODS}

\section{Data source and study population}

This study had a cross-sectional design and used baseline survey data from the Korean National Cancer Center (KNCC) Community Cohort, a community-based prospective cohort study designed to investigate the relationships between the risk of cancer and various environmental factors in Korea. This study surveyed 16,304 adults aged 30 years or older between 1993 and 2010 [15]. A total of 5,587 adults (2,125 men; 3,462 women) were recruited to the cohort from July 2003 to July 2006 and were residents of the rural areas included in the final analysis.

\section{Measures}

At the time of enrollment, well-trained interviewers conducted face-to-face interviews with participants using a structured questionnaire that elicited information on various demographic characteristics: gender, age ( $<50,50-59,60-69$, or $\geq 70$ years), job (farmer or others), marital status (couple or single), education level (no formal education, primary/middle school, high school, or higher), average household income $(1,000$ Korean won/mo; <500, 500 1,500 , or $\geq 1,500$ ), smoking status (non-smokers: $<100$ cigarettes during one's lifetime; past smokers: $\geq 100$ cigarettes during one's lifetime but did not smoke at the time of the interview; current smokers: $\geq 100$ cigarettes during one's lifetime and smoked at the time of interview), and alcohol intake (non-drinkers: $0 \mathrm{~g} / \mathrm{d}$; moderate drinkers: $<24$ g/d; heavy drinkers: $\geq 24$ g/d) [16]. Participants were asked to identify the number of times they participated in vigorous-intensity physical activity during leisure time (VPAL) (e.g., jogging, riding a bike with uphill terrain, tennis, swimming, or aerobic dancing), vigorous-intensity physical activity at work (VPAW) (e.g., carrying a heavy load, digging, rice planting, weeding, or other hard labor), and moderate-intensity physical activity (MPA) (e.g., walking, golf, balling, or riding a bike on flat terrain) during the past year. Frequency was classified as low $(<30 \mathrm{~min} / \mathrm{wk})$ and high ( $\geq 30 \mathrm{~min} / \mathrm{wk}$ ) for VPAL and as low ( $<30 \mathrm{~min} / \mathrm{wk})$, medium ( $\geq 30 \mathrm{~min} / \mathrm{wk}$ to $<1 \mathrm{hr} / \mathrm{d}$ ), and high ( $\geq 1 \mathrm{hr} / \mathrm{d}$ ) for VPAW or MPA [17]. Participants' height and weight were measured and used to calculate body mass index (BMI; $<23, \geq 23$ to $<25$, or $\geq 25 \mathrm{~kg} / \mathrm{m}^{2}$ ) [18].

\section{Statistical analysis}

The chi-square test was used to compare the distributions of various characteristics by gender. Multiple logistic regression analysis was used to determine the association between obesity and patterns of PAs adjusting for age, gender, smoking status, alcohol consumption, and household income after excluding job type, marital status, and educational attainment, all of which showed collinearity with household income. The combined effect of PA with other independent variables was analyzed to determine the impact of PA on obesity. Data were analyzed using SAS version 9.2 (SAS Institute Inc., Cary, NC, USA). All statistical significance testing was 2 -sided with an $\alpha$-error of 0.05 .

\section{Ethics statement}

The study protocol was approved by the Institutional Review Board (IRB) of the KNCC (IRB No. NCCNHS02-007; NCCNHS03-081-1; NCCNCS-07-080). All study participants signed an informed consent form before inclusion in their respective cohort.

\section{RESULTS}

More than $80 \%$ of study participants were older than 50 years and had less than a middle school education. More than half of participants were farmers and had a low household income. The prevalence of current smoking and ever drinking alcohol were $19.1 \%$ and $34.5 \%$, respectively. While only $14.9 \%$ of participants had high levels of VPAL, $41.0 \%$ had high levels of VPAW. The prevalence of obesity was $36.5 \%$ and reached $61.4 \%$ when overweight participants were included.

Men were more educated and had a higher income than women. Ever smoking, ever drinking alcohol, and higher VPAL and VPAW were more prevalent in men than in women. By contrast, higher MPA was more prevalent in women than in men. In addition, women had a higher prevalence of obesity than men ( 40.8 vs. 29.3\%) (Table 1).

Having higher VPAW showed an inverse association with obesity in both men (low vs. middle: odds ratio [OR], 0.60; 95\% confidence interval [CI], 0.45 to 0.81 ; low vs. high: OR, 0.50; $95 \% \mathrm{CI}$, 0.39 to 0.63 ) and women (low vs. middle: OR, $0.74 ; 95 \% \mathrm{CI}, 0.59$ to 0.92 ; low vs. high: OR, $0.64 ; 95 \% \mathrm{CI}, 0.54$ to 0.75 ) after adjusting for other variables as appropriate. However, VPAL and MPA 
Table 1. General characteristics and physical activities of study subjects

\begin{tabular}{|c|c|c|c|c|}
\hline Characteristics & Total & Men & Women & $p$-value \\
\hline Total & $5,587(100)$ & $2,125(38.0)$ & $3,462(62.0)$ & \\
\hline Age (yr) & & & & $<0.001^{1}$ \\
\hline$<50$ & $1,019(18.2)$ & $347(16.3)$ & $672(19.4)$ & \\
\hline $50-59$ & $1,273(22.8)$ & $490(23.1)$ & $783(22.6)$ & \\
\hline $60-69$ & $2,185(39.1)$ & $815(38.4)$ & $1,370(39.6)$ & \\
\hline$\geq 70$ & $1,110(19.9)$ & $473(22.3)$ & $637(18.4)$ & \\
\hline Job & & & & $<0.001^{1}$ \\
\hline Farmer & $2,968(57.3)$ & $1,301(65.9)$ & $1,667(52.0)$ & \\
\hline Others & $2,212(42.7)$ & $674(34.1)$ & $1,538(48.0)$ & \\
\hline Marital status & & & & $<0.001^{1}$ \\
\hline Couple & $4,154(76.1)$ & $1,928(92.4)$ & $2,226(65.9)$ & \\
\hline Single & $1,308(24.0)$ & $158(7.6)$ & $1,150(34.1)$ & \\
\hline Educational attainment & & & & $<0.001^{1}$ \\
\hline No formal education & $855(25.3)$ & $151(11.5)$ & $704(34.0)$ & \\
\hline Primary or middle school & $1,908(56.4)$ & $778(59.1)$ & $1,130(54.6)$ & \\
\hline High school or more & $623(18.4)$ & $388(29.5)$ & $235(11.4)$ & \\
\hline Household income ( $10^{3}$ Korean won/mo) & & & & $<0.001^{2}$ \\
\hline Low $(<500)$ & $2,716(50.9)$ & $872(42.6)$ & $1,844(56.1)$ & \\
\hline Middle $(500-1,500)$ & $1,492(28.0)$ & $644(31.5)$ & $848(25.8)$ & \\
\hline High $(\geq 1,500)$ & $1,130(21.2)$ & $532(26.0)$ & $598(18.2)$ & \\
\hline Smoking & & & & $<0.001^{1}$ \\
\hline Non-smoker & $3,528(63.9)$ & $398(18.9)$ & $3,130(91.8)$ & \\
\hline Former smoker & $937(17.0)$ & $831(39.4)$ & $106(3.1)$ & \\
\hline Current smoker & $1,053(19.1)$ & $881(41.8)$ & $172(5.1)$ & \\
\hline Alcohol intake (g/d) & & & & $<0.001^{2}$ \\
\hline Non-drinking & $3,368(65.5)$ & $670(34.3)$ & $2,698(84.4)$ & \\
\hline Moderate drinking $(<24)$ & $1,036(20.1)$ & $597(30.6)$ & $439(13.7)$ & \\
\hline Heavy drinking $(\geq 24)$ & $742(14.4)$ & $684(35.1)$ & $58(1.8)$ & \\
\hline Vigorous-intensity physical activity at leisure time ( $\mathrm{min} / \mathrm{wk})$ & & & & $<0.001^{1}$ \\
\hline $\operatorname{Low}(<30)$ & $4,645(85.1)$ & $1,673(80.2)$ & $2,972(88.1)$ & \\
\hline High $(\geq 30)$ & $816(14.9)$ & $414(19.8)$ & $402(11.9)$ & \\
\hline Vigorous-intensity physical activity at work & & & & $<0.001^{2}$ \\
\hline Low (<30 min/wk) & $2,301(42.1)$ & $683(32.7)$ & $1,618(48.0)$ & \\
\hline Middle $(\geq 30 \mathrm{~min} / \mathrm{wk}-<1 \mathrm{hr} / \mathrm{d})$ & $923(16.9)$ & $402(19.3)$ & $521(15.4)$ & \\
\hline High ( $\geq 1 \mathrm{hr} / \mathrm{d})$ & $2,237(41.0)$ & $1,002(48.0)$ & $1,235(36.6)$ & \\
\hline Moderate-intensity physical activity & & & & $0.006^{2}$ \\
\hline Low $(<30 \mathrm{~min} / \mathrm{wk})$ & $1,064(19.5)$ & $465(22.3)$ & $599(17.8)$ & \\
\hline Middle $(\geq 30 \mathrm{~min} / \mathrm{wk}-<1 \mathrm{hr} / \mathrm{d})$ & $2,658(48.7)$ & $969(46.4)$ & $1,689(50.1)$ & \\
\hline High $(\geq 1 \mathrm{hr} / \mathrm{d})$ & $1,739(31.8)$ & $653(31.3)$ & $1,086(32.2)$ & \\
\hline Body mass index $\left(\mathrm{kg} / \mathrm{m}^{2}\right)$ & & & & $<0.001^{2}$ \\
\hline$<23$ & $2,140(38.6)$ & $928(44.2)$ & $1,212(35.3)$ & \\
\hline $23-25$ & $1,380(24.9)$ & $558(26.6)$ & $822(23.9)$ & \\
\hline$\geq 25$ & $2,020(36.5)$ & $616(29.3)$ & $1,404(40.8)$ & \\
\hline
\end{tabular}

Values are presented as number (\%).

${ }^{1}$ Chi-square test.

${ }^{2}$ Mantel-Haenszel chi-square test.

did not show any significant associations with obesity. Age older than 60 years, a low income, and current smoking were associated with obesity in men. Being aged 50-59 years and drinking mod- erately were associated with obesity in women (Table 2).

Regardless of smoking status, alcohol intake, household income, and the level of VPAL, a higher level of VPAW was a pro- 


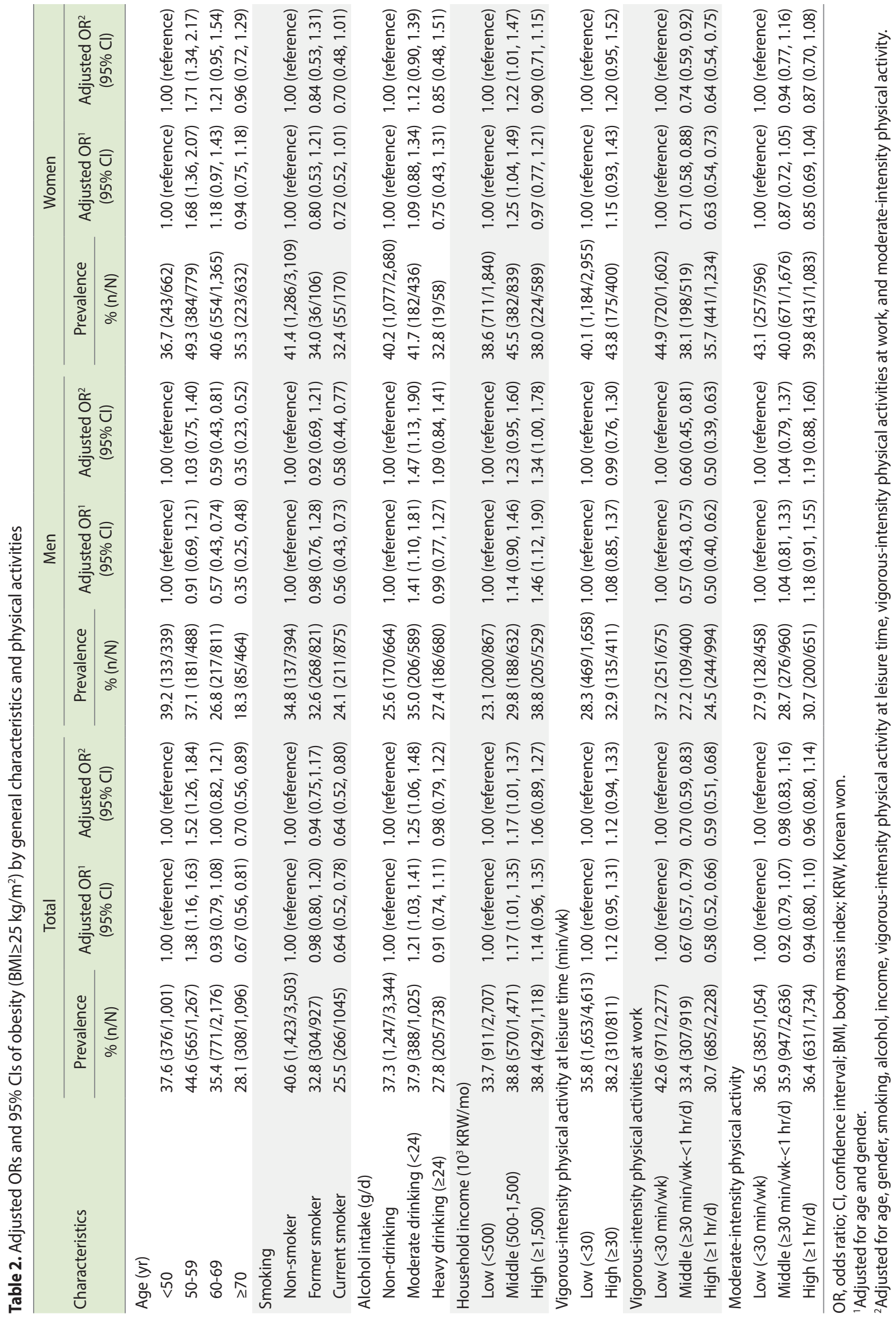


Table 3. Adjusted ORs and $95 \%$ Cls of obesity $\left(B M I>25 \mathrm{~kg} / \mathrm{m}^{2}\right)$ according to the combination of VPAW with smoking, alcohol intake, household income, and vigorous-intensity recreational physical activities

\begin{tabular}{|c|c|c|c|c|c|c|}
\hline \multirow[b]{2}{*}{ Variables } & \multicolumn{2}{|c|}{ Total } & \multicolumn{2}{|c|}{ Men } & \multicolumn{2}{|c|}{ Women } \\
\hline & $\begin{array}{l}\text { Adjusted OR' } \\
\quad(95 \% \mathrm{Cl})\end{array}$ & $\begin{array}{l}\text { Adjusted } \mathrm{OR}^{2} \\
\qquad(95 \% \mathrm{Cl})\end{array}$ & $\begin{array}{l}\text { Adjusted OR }{ }^{1} \\
\qquad(95 \% \mathrm{Cl})\end{array}$ & $\begin{array}{c}\text { Adjusted OR }{ }^{2} \\
\quad(95 \% \mathrm{Cl})\end{array}$ & $\begin{array}{l}\text { Adjusted OR }{ }^{1} \\
\quad(95 \% \mathrm{Cl})\end{array}$ & $\begin{array}{c}\text { Adjusted OR } \\
(95 \% \mathrm{Cl})\end{array}$ \\
\hline \multicolumn{7}{|l|}{ VPAW/Smoking status ${ }^{3}$} \\
\hline Low/Non-smoker & 1.00 (reference) & 1.00 (reference) & 1.00 (reference) & 1.00 (reference) & 1.00 (reference) & 1.00 (reference) \\
\hline Low/Current smoker & $0.79(0.61,1.01)$ & $0.85(0.65,1.12)$ & $0.69(0.49,0.96)$ & $0.80(0.55,1.16)$ & $0.78(0.50,1.22)$ & $0.77(0.47,1.26)$ \\
\hline Middle+High/Non-smoker & $0.64(0.57,0.73)$ & $0.66(0.58,0.76)$ & $0.59(0.45,0.76)$ & $0.61(0.46,0.81)$ & $0.65(0.57,0.76)$ & $0.67(0.57,0.78)$ \\
\hline Middle+High/Current smoker & $0.37(0.30,0.46)$ & $0.37(0.29,0.48)$ & $0.31(0.23,0.41)$ & $0.33(0.24,0.44)$ & $0.44(0.26,0.74)$ & $0.43(0.25,0.75)$ \\
\hline \multicolumn{7}{|l|}{ VPAW/Alcohol intake (g/d) } \\
\hline Low/Non-drinking & 1.00 (reference) & 1.00 (reference) & 1.00 (reference) & 1.00 (reference) & 1.00 (reference) & 1.00 (reference) \\
\hline Low/Moderate drinking $(<24)$ & $1.14(0.90,1.45)$ & $1.20(0.94,1.53)$ & $1.45(0.96,2.17)$ & $1.57(1.03,2.39)$ & $0.96(0.70,1.32)$ & $1.00(0.72,1.39)$ \\
\hline Low/Heavy drinking ( $\geq 24)$ & $1.16(0.84,1.61)$ & $1.21(0.87,1.69)$ & $1.21(0.80,1.84)$ & $1.28(0.83,1.99)$ & $0.99(0.44,2.22)$ & $1.08(0.47,2.46)$ \\
\hline Middle+High/Non-drinking & $0.63(0.55,0.73)$ & $0.63(0.55,0.74)$ & $0.56(0.39,0.80)$ & $0.59(0.41,0.87)$ & $0.66(0.56,0.77)$ & $0.65(0.55,0.77)$ \\
\hline Middle+High/Moderate drinking $(<24)$ & $0.82(0.67,1.01)$ & $0.82(0.66,1.01)$ & $0.83(0.58,1.18)$ & $0.84(0.58,1.22)$ & $0.80(0.60,1.06)$ & $0.79(0.59,1.06)$ \\
\hline Middle+High/Heavy drinking $(\geq 24)$ & $0.54(0.41,0.69)$ & $0.56(0.43,0.73)$ & $0.54(0.38,0.77)$ & $0.58(0.40,0.85)$ & $0.42(0.19,0.94)$ & $0.44(0.19,1.00)$ \\
\hline \multicolumn{7}{|l|}{ VPAW ${ }^{4} /$ Household income $\left(10^{3} \mathrm{KRW} / \mathrm{mo}\right)$} \\
\hline Low/Low $(<500)$ & 1.00 (reference) & 1.00 (reference) & 1.00 (reference) & 1.00 (reference) & 1.00 (reference) & 1.00 (reference) \\
\hline Low/Middle $(500-1,500)$ & $1.23(0.99,1.53)$ & $1.26(1.00,1.59)$ & $1.36(0.90,2.05)$ & $1.58(1.02,2.46)$ & $1.24(0.96,1.61)$ & $1.23(0.93,1.63)$ \\
\hline Low/High $(\geq 1,500)$ & $0.75(0.59,0.96)$ & $0.74(0.58,0.96)$ & $1.21(0.80,1.81)$ & $1.30(0.84,2.01)$ & $0.61(0.45,0.83)$ & $0.57(0.41,0.78)$ \\
\hline Middle+High/Low $(<500)$ & $0.52(0.44,0.62)$ & $0.55(0.46,0.66)$ & $0.49(0.35,0.68)$ & $0.57(0.40,0.82)$ & $0.55(0.45,0.67)$ & $0.57(0.46,0.69)$ \\
\hline Middle+High/Middle $(500-1,500)$ & $0.62(0.51,0.75)$ & $0.63(0.51,0.77)$ & $0.57(0.41,0.8)$ & $0.63(0.44,0.91)$ & $0.69(0.54,0.88)$ & $0.68(0.53,0.87)$ \\
\hline Middle+High/High $(\geq 1,500)$ & $0.77(0.62,0.97)$ & $0.78(0.62,0.99)$ & $0.75(0.52,1.08)$ & $0.79(0.53,1.16)$ & $0.80(0.59,1.08)$ & $0.80(0.59,1.10)$ \\
\hline \multicolumn{7}{|l|}{ VPAW $^{4} / \mathrm{VPAL}^{5}$} \\
\hline Low/Low & 1.00 (reference) & 1.00 (reference) & 1.00 (reference) & 1.00 (reference) & 1.00 (reference) & 1.00 (reference) \\
\hline Low/High & $0.84(0.65,1.09)$ & $0.81(0.61,1.07)$ & $0.71(0.47,1.08)$ & $0.69(0.44,1.10)$ & $0.89(0.64,1.25)$ & $0.83(0.58,1.20)$ \\
\hline Middle+High/Low & $0.56(0.5,0.64)$ & $0.58(0.51,0.66)$ & $0.45(0.36,0.57)$ & $0.48(0.37,0.61)$ & $0.61(0.53,0.71)$ & $0.62(0.53,0.73)$ \\
\hline Middle+High/High & $0.77(0.63,0.95)$ & $0.78(0.63,0.97)$ & $0.61(0.44,0.83)$ & $0.58(0.41,0.81)$ & $0.89(0.67,1.18)$ & $0.94(0.70,1.25)$ \\
\hline
\end{tabular}

$\mathrm{OR}$, odds ratio; $\mathrm{Cl}$, confidence interval; BMI, body mass index; VPAW, vigorous-intensity physical activity at work; KRW, Korean won; VPAL, vigorousintensity physical activity during leisure time.

${ }^{1}$ Adjusted for age and gender.

${ }^{2}$ Adjusted for age, gender, smoking, alcohol intake, and household income.

${ }^{3}$ Non-smoker: non-smokers and former smokers.

${ }^{4}$ VPAW: low $(<30 \mathrm{~min} / \mathrm{wk})$, middle $(\geq 30 \mathrm{~min} / \mathrm{wk}-<1 \mathrm{hr} / \mathrm{d})$, high $(\geq 1 \mathrm{hr} / \mathrm{d})$.

${ }^{5}$ PPAL: low (<30 min/wk), high ( $\left.\geq 30 \mathrm{~min} / \mathrm{wk}\right)$.

tective factor associated with obesity, and these results remained similar in both genders. In addition, high household income significantly reduced the risk of obesity among women who engaged in low-intensity PA (Table 3).

\section{DISCUSSION}

This is the first study to evaluate the associations of different patterns of PA and obesity among older adults in rural areas. The obesity prevalence in the present study was moderately higher than that in the national data of the same year (36.5 vs. $31.3 \%)$. Furthermore, even though the national data indicated a higher obesity prevalence in men than in women (34.7 vs. $27.3 \%$ ), the present results showed a higher prevalence in women (40.8 vs. $29.3 \%$ ). The higher prevalence of obesity may be attributed to the older age of most participants, as previous studies have found a relatively high obesity prevalence in this population $[19,20]$. In general, aging is considered a risk factor for obesity due to excess fat accumulation with lower basal metabolism led by changes in lifestyle with retirement, chronic positive energy balance, and lack of PA associated with age-related diseases. In particular, the hormonal effects caused by menopause could result in greater increases of obesity in women at menopausal age, as suggested by the results of the current study. However, this trend stops or even reverses in those aged more than 60 years, as found in the current study results, with a decrease of obesity prevalence in men after adjusting for the effects of other covariates [21].

One of the major findings of the present study is the lack of a protective effect of VPAL in the study population. This result contrasts with the findings of numerous studies that have confirmed leisure-time PA to be one of the main strategies for obesity prevention [4,22-25]. Interestingly, this difference in the effect of 
VPAL on obesity may be explained by the population. Most study participants (85.0\%) had low levels of leisure-time PA, possibly due to low income and educational levels as well as insufficient facilities for physical exercise in rural communities [26,27]. Instead, the only robust association seen in our study was between VPAW and obesity, regardless of smoking status, alcohol intake, or the level of VPAL. Many studies on the effect of VPAW and obesity have generally shown less consistent results. Some of these studies suggested no associations between VPAW and obesity $[19,24,28,29]$, while others found inverse or positive associations of VPAW with obesity [20,30,31]. Stamatakis et al. [32] reported that domestic activity did not appear to be protective toward obesity, as these types of PAs differ from leisure-time PA. PA during leisure time is characterized by the use of large muscle groups, whereas PA at work mainly utilizes smaller upper-body muscles and is more intermittent, less rhythmic, and often non-locomotory. However, the inverse association observed herein between VPAW and obesity could be explained by the characteristics of the study participants. More than half of the participants were farmers, which is an occupational sector that demands more heavy-intensity work [33]. PA involving heavy-intensity work can reduce the risk of obesity, especially for those who participate in hard manual labor in rural areas [33], as suggested in several previous studies that have reported similar results $[20,34]$. These findings were consistent after adjusting for other covariates and combined with other potential attributable factors that may be associated with VPAW or obesity. Therefore, the findings provide valuable public health implications for the development and implementation of weight gain prevention strategies, particularly in rural areas where limited attention has been paid to these issues.

Smoking also independently contributed to obesity. In most studies, non-smokers were found have a significantly higher average BMI than smokers [35,36], and our results are in line with this. Nicotine may increase basal metabolism, and smoking cessation could increase weight gain without routine PAs. Compared with non-drinking, moderate (but not heavy) alcohol drinking was associated with a slightly increased prevalence of obesity in the current study. According to our results, 1 or 2 drinks per day decreased the odds of obesity. These results do not match those of other previous studies that suggested an inverse association between increased alcohol consumption and weight gain [37]. Higher alcohol consumption could be a reason for obesity, through the additional calorie intake from alcohol consumption, or a reason for weight loss due to malnutrition caused by inappropriate nutrient and calorie intake among heavy drinkers. Among study participants, the proportion of heavy drinking was low in men and rare in women since drinking is not as socially acceptable for women. Meanwhile, moderate drinking was identified as positively associated with obesity in men. High household income was significantly associated with decreased obesity in men, but only middle income showed a significant positive association with obesity in women. The associations remained still significant after excluding other covariates including VPAW. Pos- sible explanations include the possibility that higher socioeconomic status could allow people to consider and implement a positive lifestyle, including a healthy diet, or lead to excess calorie intake due to misconceptions about appropriate eating. This relationship may also depend on individuals' access to and understanding of appropriate information for maintaining a healthy weight with social support and relationships to help them, even if these factors were not considered in the present study.

Although the associations of VPAW and household income with obesity in an aged, rural population are novel findings, this study had several limitations. Due to the nature of this cross-sectional study, we could not determine the temporal relationship between VPAW and obesity. Present challenges for clarifying the true impact of PA on weight gain or reduction should continue to be researched in general populations with longitudinal designs, because another study showed evidence that obesity may be a barrier to engaging in PA [38]. In addition, PA is related to both energy expenditure and energy intake, which cannot be easily and accurately measured at the population level. Recalling past PA is a highly complex cognitive task that may not provide accurate estimates in absolute amounts or may have differential outcomes between the young and very old due to the use of ambiguous terms such as "physical activity," "vigorous intensity," and "leisure time" $[39,40]$. Nonetheless, the present study results are unlikely to be distorted by this issue, as a standardized questionnaire was applied to estimate PA and the study population was relatively homogeneous in terms of age, residential area, education, and job. Diet is another important factor associated with obesity that was not measured or considered in the present study. However, it is reasonable to assume that the effects of diet would be the same across the strata of PA and other potential factors, as no reason was found to hypothesize the presence of differences in diet by strata.

There is little question as to the importance of PA for weight management, and our study provides further evidence for the positive effects of vigorous occupational PA on obesity. These results indicate that activity derived from a physically active occupation can reduce obesity, especially for those who participate in hard manual labor in rural areas. Meanwhile, vigorous leisuretime PA did not reduce weight gain. These findings will have important public health implications for the development and implementation of weight gain prevention strategies.

\section{CONFLICT OF INTEREST}

The authors have no conflicts of interest to declare for this study.

\section{FUNDING}

This study was financially supported by National Cancer Center Grants NCC-0410130 and NCC-0710140. 


\section{ACKNOWLEDGEMENTS}

The authors appreciate all cohort members in the community who participated voluntarily in the study. We also thank all collaborators, including those from the public health centers of Haman-gun, Changwon-si, Chungju-si and Chuncheon-si, and the Health Center and County Hospital of Sancheong-gun.

\section{AUTHOR CONTRIBUTIONS}

Conceptualization: MKL. Data curation: SYK. Formal analysis: HC. Funding acquisition: MKL. Methodology: MKL, JKO. Project administration: MKL. Visualization: SYK, TTPT. Writing original draft: SYK, MKL, TTPT. Writing - review \& editing: MKL, JKO, HC.

\section{ORCID}

Su Yeon Kye: http://orcid.org/0000-0003-2535-3518; Heeyoun Cho: http://orcid.org/0000-0002-1553-0763; Tran Thi Phuong Thao: http://orcid.org/0000-0003-4708-6027; Jin Kyoung Oh: http://orcid. org/0000-0001-9331-3054; Min Kyung Lim: http://orcid.org/00000002-8224-2171

\section{REFERENCES}

1. Müller MJ, Geisler C. From the past to future: from energy expenditure to energy intake to energy expenditure. Eur J Clin Nutr 2017; 71:358-364.

2. Romieu I, Dossus L, Willett WC. Energy balance and obesity. IARC Working Group reports, No. 10; 2017 [cited 2021 Jan 7]. Available from: https://publications.iarc.fr/Book-And-Report-Series/IarcWorking-Group-Reports/Energy-Balance-And-Obesity-2017.

3. Finkelstein EA, Khavjou OA, Thompson H, Trogdon JG, Pan L, Sherry B, et al. Obesity and severe obesity forecasts through 2030. Am J Prev Med 2012;42:563-570.

4. Balboa-Castillo T, Guallar-Castillón P, León-Muñoz LM, Graciani A, López-García E, Rodríguez-Artalejo F. Physical activity and mortality related to obesity and functional status in older adults in Spain. Am J Prev Med 2011;40:39-46.

5. Drøyvold WB, Holmen J, Midthjell K, Lydersen S. BMI change and leisure time physical activity (LTPA): an 11-y follow-up study in apparently healthy men aged 20-69 y with normal weight at baseline. Int J Obes Relat Metab Disord 2004;28:410-417.

6. Li K, Seo DC, Torabi MR, Peng CY, Kay NS, Kolbe LJ. Leisure-time physical activity and obesity in black adults in Indianapolis. Am J Health Behav 2010;34:442-452.

7. Seo DC, Li K. Leisure-time physical activity dose-response effects on obesity among US adults: results from the 1999-2006 National Health and Nutrition Examination Survey. J Epidemiol Community Health 2010;64:426-431.

8. Banks E, Lim L, Seubsman SA, Bain C, Sleigh A. Relationship of obesity to physical activity, domestic activities, and sedentary be- haviours: cross-sectional findings from a national cohort of over 70,000 Thai adults. BMC Public Health 2011;11:762.

9. Church TS, Thomas DM, Tudor-Locke C, Katzmarzyk PT, Earnest CP, Rodarte RQ, et al. Trends over 5 decades in U.S. occupation-related physical activity and their associations with obesity. PLoS One 2011;6:e19657.

10. Gay JL, Buchner DM, Smith J. Occupational physical activity opposes obesity: a cross-sectional modern replication of the Morris 1953 London Busmen Study. J Occup Environ Med 2019;61:177182.

11. Steeves JA, Bassett DR Jr, Thompson DL, Fitzhugh EC. Relationships of occupational and non-occupational physical activity to abdominal obesity. Int J Obes (Lond) 2012;36:100-106.

12. Baik I. Forecasting obesity prevalence in Korean adults for the years 2020 and 2030 by the analysis of contributing factors. Nutr Res Pract 2018;12:251-257.

13. Korea Centers for Disease Control and Prevention (KCDC). National health statistics; Cheongju: KCDC; 2019, p. 227 (Korean).

14. Jeong HG, Kim DY, Kang DW, Kim BJ, Kim CK, Kim Y, et al. Physical activity frequency and the risk of stroke: a nationwide cohort study in Korea. J Am Heart Assoc 2017;6:e005671.

15. Oh JK, Lim MK, Yun EH, Choi MH, Hong ST, Chang SH, et al. Cohort profile: community-based prospective cohort from the National Cancer Center, Korea. Int J Epidemiol 2017;46:e14.

16. National Institute on Alcohol Abuse and Alcoholism. Alcohol alert; 1992 [cited 2020 Nov 1]. Available from: https://pubs.niaaa.nih. gov/publications/aa16.htm.

17. U.S. Department of Health and Human Services. 2018 Physical Activity Guidelines Advisory Committee scientific report. Washington, DC: U.S. Department of Health and Human Services; 2018, p. 7-11.

18. WHO Expert Consultation. Appropriate body-mass index for Asian populations and its implications for policy and intervention strategies. Lancet 2004;363:157-163.

19. Ball K, Owen N, Salmon J, Bauman A, Gore CJ. Associations of physical activity with body weight and fat in men and women. Int J Obes Relat Metab Disord 2001;25:914-919.

20. Hajian-Tilaki KO, Heidari B. Prevalence of obesity, central obesity and the associated factors in urban population aged 20-70 years, in the north of Iran: a population-based study and regression approach. Obes Rev 2007;8:3-10.

21. Xu W, Zhang H, Paillard-Borg S, Zhu H, Qi X, Rizzuto D. Prevalence of overweight and obesity among Chinese adults: role of adiposity indicators and age. Obes Facts 2016;9:17-28.

22. Brach JS, VanSwearingen JM, FitzGerald SJ, Storti KL, Kriska AM. The relationship among physical activity, obesity, and physical function in community-dwelling older women. Prev Med 2004; 39:74-80.

23. Barengo NC, Kastarinen M, Lakka T, Nissinen A, Tuomilehto J. Different forms of physical activity and cardiovascular risk factors among 24-64-year-old men and women in Finland. Eur J Cardiovasc Prev Rehabil 2006;13:51-59.

24. Sofi F, Capalbo A, Marcucci R, Gori AM, Fedi S, Macchi C, et al. 
Leisure time but not occupational physical activity significantly affects cardiovascular risk factors in an adult population. Eur J Clin Invest 2007;37:947-953.

25. Tudor-Locke C, Burton NW, Brown WJ. Leisure-time physical activity and occupational sitting: associations with steps/day and BMI in 54-59 year old Australian women. Prev Med 2009;48:6468.

26. Park T, Eyler AA, Tabak RG, Valko C, Brownson RC. Opportunities for promoting physical activity in rural communities by understanding the interests and values of community members. J Environ Public Health 2017;2017:8608432.

27. Bryan S, Walsh P. Physical activity and obesity in Canadian women. BMC Womens Health 2004;4 Suppl 1(Suppl 1):S6.

28. Gutiérrez-Fisac JL, Guallar-Castillón P, Díez-Gañán L, García EL, Banegas JR, Artalejo FR. Work-related physical activity is not associated with body mass index and obesity. Obes Res 2002;10: 270-276

29. Kaleta D, Makowiec-Dabrowska T, Jegier A. Occupational and leisure-time energy expenditure and body mass index. Int J Occup Med Environ Health 2007;20:9-16.

30. Larsson CA, Krøll L, Bennet L, Gullberg B, Råstam L, Lindblad U. Leisure time and occupational physical activity in relation to obesity and insulin resistance: a population-based study from the Skaraborg Project in Sweden. Metabolism 2012;61:590-598.

31. Pols MA, Peeters PH, Twisk JW, Kemper HC, Grobbee DE. Physical activity and cardiovascular disease risk profile in women. Am J Epidemiol 1997;146:322-328.

32. Stamatakis E, Hirani V, Rennie K. Moderate-to-vigorous physical activity and sedentary behaviours in relation to body mass index- defined and waist circumference-defined obesity. Br J Nutr 2009; 101:765-773.

33. Choi B, Schnall PL, Yang H, Dobson M, Landsbergis P, Israel L, et al. Sedentary work, low physical job demand, and obesity in US workers. Am J Ind Med 2010;53:1088-1101.

34. King GA, Fitzhugh EC, Bassett DR Jr, McLaughlin JE, Strath SJ, Swartz AM, et al. Relationship of leisure-time physical activity and occupational activity to the prevalence of obesity. Int J Obes Relat Metab Disord 2001;25:606-612.

35. Bakhshi E, Eshraghian MR, Mohammad K, Foroushani AR, Zeraati $\mathrm{H}$, Fotouhi A, et al. Sociodemographic and smoking associated with obesity in adult women in Iran: results from the National Health Survey. J Public Health (Oxf) 2008;30:429-435.

36. Kawada T. Difference of body mass index stratified by the period of smoking cessation from a cross-sectional study. Arch Med Res 2004;35:181-184.

37. Vadstrup ES, Petersen L, Sørensen TI, Grønbaek M. Waist circumference in relation to history of amount and type of alcohol: results from the Copenhagen City Heart Study. Int J Obes Relat Metab Disord 2003;27:238-246.

38. Lakerveld J, Dunstan D, Bot S, Salmon J, Dekker J, Nijpels G, et al. Abdominal obesity, TV-viewing time and prospective declines in physical activity. Prev Med 2011;53:299-302.

39. Baranowski, T. Validity and reliability of self report measures of physical activity: an information-processing perspective. Res Q Exerc Sport 1988;59:314-327.

40. Sallis JF, Saelens BE. Assessment of physical activity by self-report: status, limitations, and future directions. Res Q Exerc Sport 2000;71(2 Suppl):S1-S14. 